\title{
Electromagnetic and microwave absorbing properties of hollow carbon nanospheres
}

\author{
TIANCHUN ZOU ${ }^{1, *}$, HAIPENG LI ${ }^{2}$, NAIQIN ZHAO ${ }^{3}$ and CHUNSHENG SHI ${ }^{3}$ \\ ${ }^{1}$ Airworthiness Certification Technology Research and Management Centre, Civil Aviation University of China, \\ Tianjin 300 300, China \\ ${ }^{2}$ School of Materials Science and Engineering, Hebei University of Technology, Tianjin 300 130, China \\ ${ }^{3}$ School of Materials Science and Engineering, Tianjin University, Tianjin 300 072, China
}

MS received 2 March 2012; revised 30 April 2012

\begin{abstract}
A mass of hollow carbon nanospheres (HCNSs) was fabricated by chemical vapour deposition of methane over $\mathrm{Ni} / \mathrm{Al}_{2} \mathrm{O}_{3}$ catalyst at $600^{\circ} \mathrm{C}$. The products were characterized with high-resolution transmission electron microscope images, and the results showed that the external diameter of the HCNSs was 5-90 nm and the thickness of wall was about $10 \mathrm{~nm}$. Microwave absorption of HCNSs/paraffin composites was mainly attributed to dielectric loss. The microwave-absorbing peaks of composites containing HCNSs shifts to low frequencies, and the bandwidth below $-10 \mathrm{~dB}$ and minimum RL decrease with increasing thickness of HCNSs/paraffin composites.
\end{abstract}

Keywords. Nanomaterials; nanospheres; CVD; electric; magnetic; microwave absorption properties.

\section{Introduction}

In recent years, microwave absorbing materials have attracted considerable attention because it is an essential part of a stealthy defense system for all military platforms, either as aircraft, sea or land vehicles. They are also used to eliminate electromagnetic interference (EMI), which is a specific kind of environmental pollution due to the explosive growth in the utilization of electrical and electronic devices in industrial and commercial applications (Bayrakdar 2011; Nam et al 2011; Zhang and Sun 2012).

Carbon materials, which are considered as the most promising absorbents since world war II, have been widely employed in microwave-absorbing materials in reducing backscattering from objects or radar targets, EMI suppressors and paints (Ting et al 2012; Zhai et al 2012). Recently, hollow-carbon nanospheres (HCNSs), which represent a special class of materials, have been attracting intense interest because of their diverse potential applications in drug delivery, heterogeneous catalysis, dye encapsulation, contaminated waste removal and the protection of enzymes and proteins, etc. (Li et al 2009, 2010; Zhu et al 2012). However, to the best of our knowledge, little has been reported about HCNSs' performance of applications such as microwave absorbent in the open literature. The present work attempts to investigate electromagnetic and microwave absorbing properties of HCNSs synthesized by the catalytic method at low temperature.

\footnotetext{
*Author for correspondence (zoutianchun@yahoo.com.cn)
}

\section{Experimental}

The process for synthesizing HCNSs involved the preparation of catalyst precursor, $\mathrm{Ni}(\mathrm{OH})_{2} / \mathrm{Al}(\mathrm{OH})_{3}$, and the catalytic decomposition of methane over $\mathrm{Ni} / \mathrm{Al}_{2} \mathrm{O}_{3}$ catalyst. Previously (He et al 2006), we fabricated the Ni/Al catalyst using a precipitation route. Here also we used this process but excess $\mathrm{NaOH}$ (till the $\mathrm{pH}$ value of the solution arrived at 10) to produce binary colloid $\mathrm{Ni}(\mathrm{OH})_{2} / \mathrm{Al}(\mathrm{OH})_{3}$ (weight ratio, $\mathrm{Ni} / \mathrm{Al}=2 / 3)$. After that the colloid was calcined in air to yield clusters made of $\mathrm{Ni}$ and $\mathrm{Al}$ oxides and then reduced in a $\mathrm{H}_{2}$ flow $(100 \mathrm{ml} / \mathrm{min})$ at $600{ }^{\circ} \mathrm{C}$ for $120 \mathrm{~min}$ to form Ni nanoclusters supported on $\mathrm{Al}_{2} \mathrm{O}_{3}$. To synthesize $\mathrm{HCNSs}, 50 \mathrm{mg}$ $\mathrm{NiO} / \mathrm{Al}_{2} \mathrm{O}_{3}$ was distributed uniformly in a quartz boat and was placed into a tube furnace. When the furnace reached $600{ }^{\circ} \mathrm{C}$ under nitrogen and hydrogen $(100 \mathrm{ml} / \mathrm{min}$, $99.99 \%$ purity) was introduced to reduce the catalyst for $2 \mathrm{~h}$. Then the hydrogen flow was stopped, and a mixture of $\mathrm{CH}_{4} / \mathrm{N}_{2}(60 / 420 \mathrm{ml} / \mathrm{min}, \mathrm{v} / \mathrm{v})$ was introduced into the tube and maintained for $1 \mathrm{~h}$. After the growth, the furnace was cooled to room temperature under $\mathrm{N}_{2}$ and black powder was obtained. The black mixture was added in a round-bottomed flask containing distilled water and dispersed sufficiently by ultrasonication for $1 \mathrm{~h}$. The resultant HCNSs were collected by centrifugation, then they were dried at $80^{\circ} \mathrm{C}$ in an oven for 2 days. After cooling it to ambient temperature naturally, the final products were obtained.

The morphology of as-grown HCNSs was characterized using transmission electron microscope (TEM) (Philips Tecnai $G^{2}$ F20, $200 \mathrm{kV}$ ). Co-axial line method was used to determine the electromagnetic parameters of HCNSs/ paraffin composite with a HP8722ES vector network 
analyser in the frequency range of $2-18 \mathrm{GHz} .5 \mathrm{wt} \% \mathrm{HCNSs}$ were mixed with paraffin and prepared as the toroidal shape with an outer diameter of $7.0 \mathrm{~mm}$, an inner diameter of
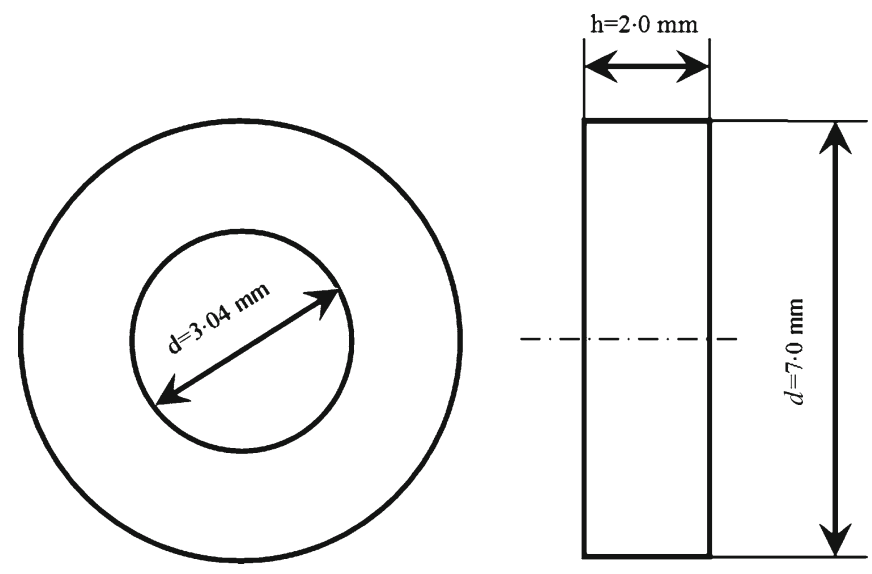

Figure 1. Toroidal shaped HCNSs/paraffin composites for electromagnetic parameter measurements.

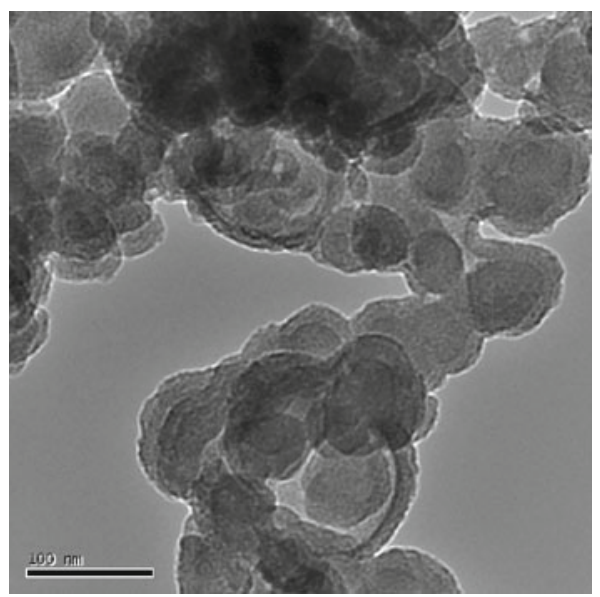

(a)
$3.04 \mathrm{~mm}$ and a thickness of $2.0 \mathrm{~mm}$ (see figure 1). The reflection loss (RL) with different thickness was calculated from equations shown below (Feng et al 2007):

$$
\begin{aligned}
& \operatorname{RL}(\mathrm{dB})=20 \log \left|\frac{Z_{\text {in }}-1}{Z_{\text {in }}+1}\right|, \\
& Z_{\text {in }}=\left(\frac{\mu_{\mathrm{r}}}{\varepsilon_{\mathrm{r}}}\right)^{1 / 2} \tan \mathrm{h}\left[j\left(\frac{2 \pi f d}{c}\right)\left(\mu_{\mathrm{r}} \varepsilon_{\mathrm{r}}\right)^{1 / 2}\right],
\end{aligned}
$$

where $Z_{\text {in }}$ is the normalized input impedance at free space and material interface, $\varepsilon_{\mathrm{r}}=\varepsilon^{\prime}-j^{\prime \prime}$ and $\mu_{\mathrm{r}}=\mu^{\prime}-j \mu^{\prime \prime}$ are the complex relative permittivity and permeability of the material, $d$ the thickness of the microwave is absorbing materials and $c$ and $f$ are the velocity of light and the frequency of microwave in free space, respectively.

In the frequency range $2-18 \mathrm{GHz}$, the complex relative permittivity and permeability of paraffin are small and almost constant $\left(\varepsilon_{\mathrm{r}} \approx 2 \cdot 0-0 j, \mu_{\mathrm{r}} \approx 1 \cdot 0-0 j\right)$. So the electromagnetic properties of HCNSs/paraffin composites mostly represent the electromagnetic performances of HCNSs.

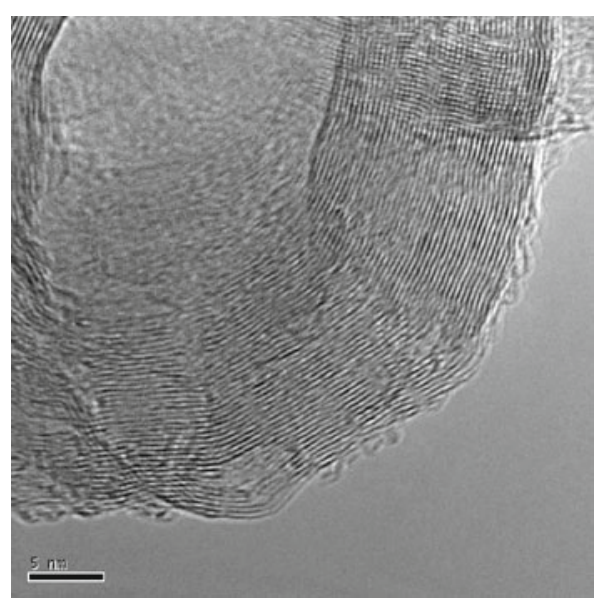

(c)

Figure 2. Typical TEM images of as-prepared HCNSs fabricated by catalytic method over $\mathrm{Ni} / \mathrm{Al}_{2} \mathrm{O}_{3}$ catalyst. 


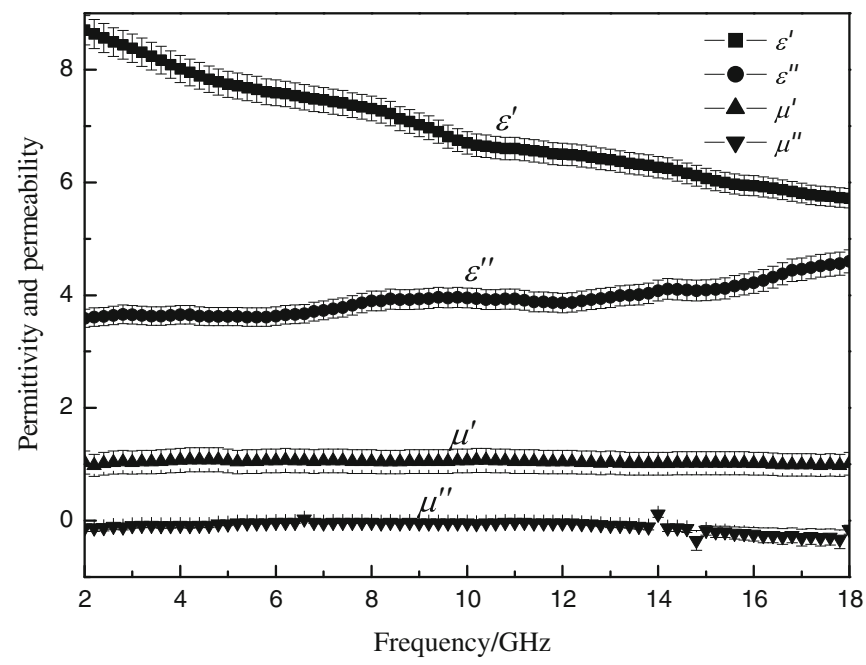

Figure 3. Permittivity and permeability spectra of HCNSs composites.

\section{Results and discussion}

A representative low-magnification TEM micrograph of the products is shown in figure 2(a). From this we can see that the external diameter of the HCNSs is $5-90 \mathrm{~nm}$ and the thickness of the wall ranges from 2 to $50 \mathrm{~nm}$. Typical HRTEM images of the HCNSs are presented in figure 2(b) and (c). Broken sphere and strong contrast between the dark edge and pale centre are revealed in figure 2(b), providing further proof of the hollow nature. Figure 2(c) shows one typical HCNS in high magnification. It indicates that the hollow spheres are composed of carbon sheets and the average wall thickness of HCNSs is about $10 \mathrm{~nm}$. The HCNSs shell consists of about 32 graphitic layers. Figure 2(c) also reveals that the sheets are well-graphitized and the interlayer spacing is about $0.34 \mathrm{~nm}$, which is consistent with the $d$ value of $\left(\begin{array}{lll}0 & 0 & 2\end{array}\right)$ plane of hexagonal graphite.

Figure 3 shows real and imaginary parts of the complex permittivity, $\varepsilon_{\mathrm{r}}\left(\varepsilon^{\prime}\right.$ and $\left.\varepsilon^{\prime \prime}\right)$ and complex permeability, $\mu_{\mathrm{r}}\left(\mu^{\prime}\right.$ and $\left.\mu^{\prime \prime}\right)$ of HCNSs/paraffin composites dependent on the frequency. As shown in figure 3 , the values of $\varepsilon^{\prime}$ are bigger than those of $\varepsilon^{\prime \prime}$, and the variation of the $\varepsilon^{\prime}$ spectrum is different from the spectrum of $\varepsilon^{\prime \prime}$. The $\varepsilon^{\prime}$ of the HCNSs composite exhibits a fall from 8.70 to 5.72 with an increase in frequency from 2 to $18 \mathrm{GHz}$, and the $\varepsilon^{\prime \prime}$ of the HCNSs composite gradually rises from 3.59 to 4.6 with an increasing frequency. The $\mu^{\prime}$ and $\mu^{\prime \prime}$ of the HCNSs composite are almost constant $\left(\mu^{\prime} \approx 1 \cdot 0, \mu^{\prime \prime} \approx 0\right.$ ) over $2-18 \mathrm{GHz}$. This is most likely to be caused by the intrinsically small magnetic loss tangent $\left(\tan \delta_{\mathrm{M}}\right)$ of HCNSs. So microwave absorption of HCNSs results mainly from dielectric loss rather than magnetic loss.

According to (1) and (2), the RL of microwave-absorbing materials is a function of six characteristic parameters: $\varepsilon^{\prime}, \varepsilon^{\prime \prime}, \mu^{\prime}, \mu^{\prime \prime}, f$ and $d$. Thus, if the parameters of the materials are known, the absorbing properties of the material for single layer coating can be calculated. RL values calculated by using (1) and (2) for measured values of

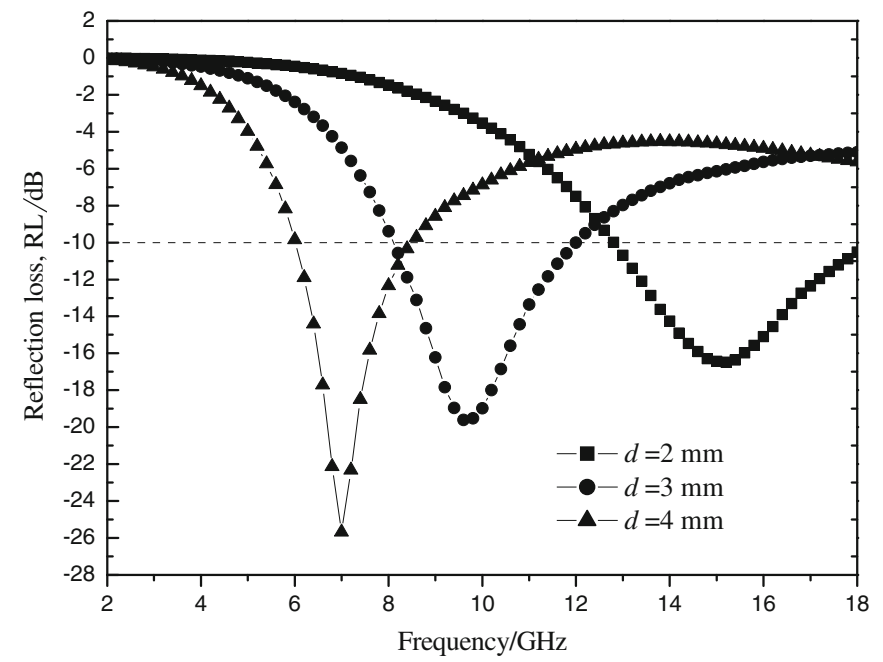

Figure 4. Microwave absorbing characteristics of HCNSs composites.

$\varepsilon^{\prime}, \varepsilon^{\prime \prime}, \mu^{\prime}$ and $\mu^{\prime \prime}$ are shown in figure 4 for HCNSs composites with different matching thickness $(d)$. It can be seen that the values of matching thickness influence the RL of HCNSs composites greatly. Microwave-absorbing peaks move towards lower frequencies with increasing $d$ values, correspondingly, the frequencies corresponding to the minimum RL values of absorbing peaks are $15.2 \mathrm{GHz}(d=$ $2 \mathrm{~mm}), 9 \cdot 6 \mathrm{GHz}(d=3 \mathrm{~mm})$ and $7.0 \mathrm{GHz}(d=4 \mathrm{~mm})$. In addition, it can be observed that the bandwidth below $-10 \mathrm{~dB}$ (90\% absorption) becomes narrower and the minimum RL decreases with the increase in the matching thickness, $d$. When the values of $d$ are 2,3 and $4 \mathrm{~mm}$, the corresponding bandwidth below $-10 \mathrm{~dB}$ and minimum RL are $5.2 \mathrm{GHz}$ and $-16.5 \mathrm{~dB}, 4.2 \mathrm{GHz}$ and $-19.6 \mathrm{~dB}, 2.6 \mathrm{GHz}$ and $-25.7 \mathrm{~dB}$, respectively.

\section{Conclusions}

In conclusion, hollow carbon nanospheres (HCNSs) were fabricated by chemical vapour deposition of methane over $\mathrm{Ni} / \mathrm{Al}_{2} \mathrm{O}_{3}$ catalyst. TEM images show that the external diameter of HCNSs was $5-90 \mathrm{~nm}$ and the thickness of the wall was about $10 \mathrm{~nm}$. Microwave absorptions of HCNSs/paraffin composites result mainly from dielectric loss rather than magnetic loss. With increasing thickness, microwave-absorbing peaks of composites containing HCNSs move towards low frequencies, and the bandwidth below $-10 \mathrm{~dB}$ and minimum RL decrease. Our studies indicate that HCNSs may have potential applications in the field of light weight microwave-absorbing materials.

\section{References}

Bayrakdar H 2011 J. Magn. Magn. Mater. 3231882

Feng Y B, Qiu T and Shen C Y 2007 J. Magn. Magn. Mater. 3188 
He C N, Du X W, Ding J, Zhao N Q and Shi C S 2006 Carbon 44 2330

Li M, Wu Q S, Wen M and Shi J L 2009 Nano. Res. Lett. 171125

Li J J, Yuan R, Chai Y Q, Zhang T T and Che X 2010 Microchim. Acta $\mathbf{1 7 1} 125$

Nam I W, Lee H K and Jang J H 2011 Compos. Part A: Appl. Sci. 421110
Ting T H, Jau Y N and Yu R P 2012 Appl. Surf. Sci. 258 3184

Zhai Y H, Zhang Y and Ren W 2012 Mater. Chem. Phys. 133 176

Zhang X Z and Sun W 2012 Procedia Eng. 27348

Zhu H L, Bai Y J, Qi Y X, Lun N and Zhu Y 2012 Carbon 50 1871 